
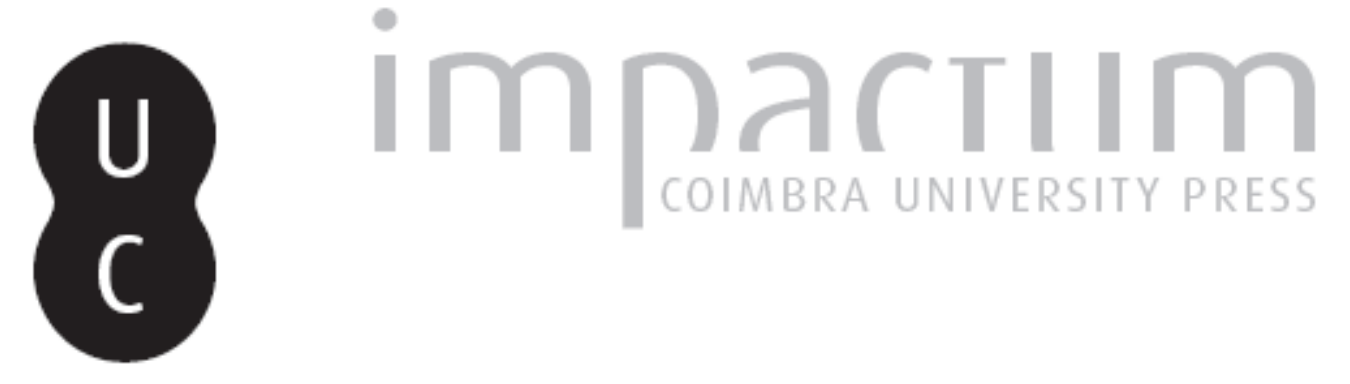

\title{
Em busca da perfeição cristã: práticas espirituais e devotas dos leigos em Portugal (séculos XVI-XVII)
}

\author{
Autor(es): $\quad$ Mendes, Paula Almeida
}

Publicado por: Imprensa da Universidade de Coimbra

URL persistente:

URI:http://hdl.handle.net/10316.2/40668

DOI:

DOI:https://doi.org/10.14195/0870-4147_47_4

Accessed : $\quad$ 26-Apr-2023 14:00:01

A navegação consulta e descarregamento dos títulos inseridos nas Bibliotecas Digitais UC Digitalis, UC Pombalina e UC Impactum, pressupõem a aceitação plena e sem reservas dos Termos e Condições de Uso destas Bibliotecas Digitais, disponíveis em https://digitalis.uc.pt/pt-pt/termos.

Conforme exposto nos referidos Termos e Condições de Uso, o descarregamento de títulos de acesso restrito requer uma licença válida de autorização devendo o utilizador aceder ao(s) documento(s) a partir de um endereço de IP da instituição detentora da supramencionada licença.

Ao utilizador é apenas permitido o descarregamento para uso pessoal, pelo que o emprego do(s) título(s) descarregado(s) para outro fim, designadamente comercial, carece de autorização do respetivo autor ou editor da obra.

Na medida em que todas as obras da UC Digitalis se encontram protegidas pelo Código do Direito de Autor e Direitos Conexos e demais legislação aplicável, toda a cópia, parcial ou total, deste documento, nos casos em que é legalmente admitida, deverá conter ou fazer-se acompanhar por este aviso.

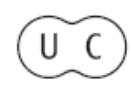




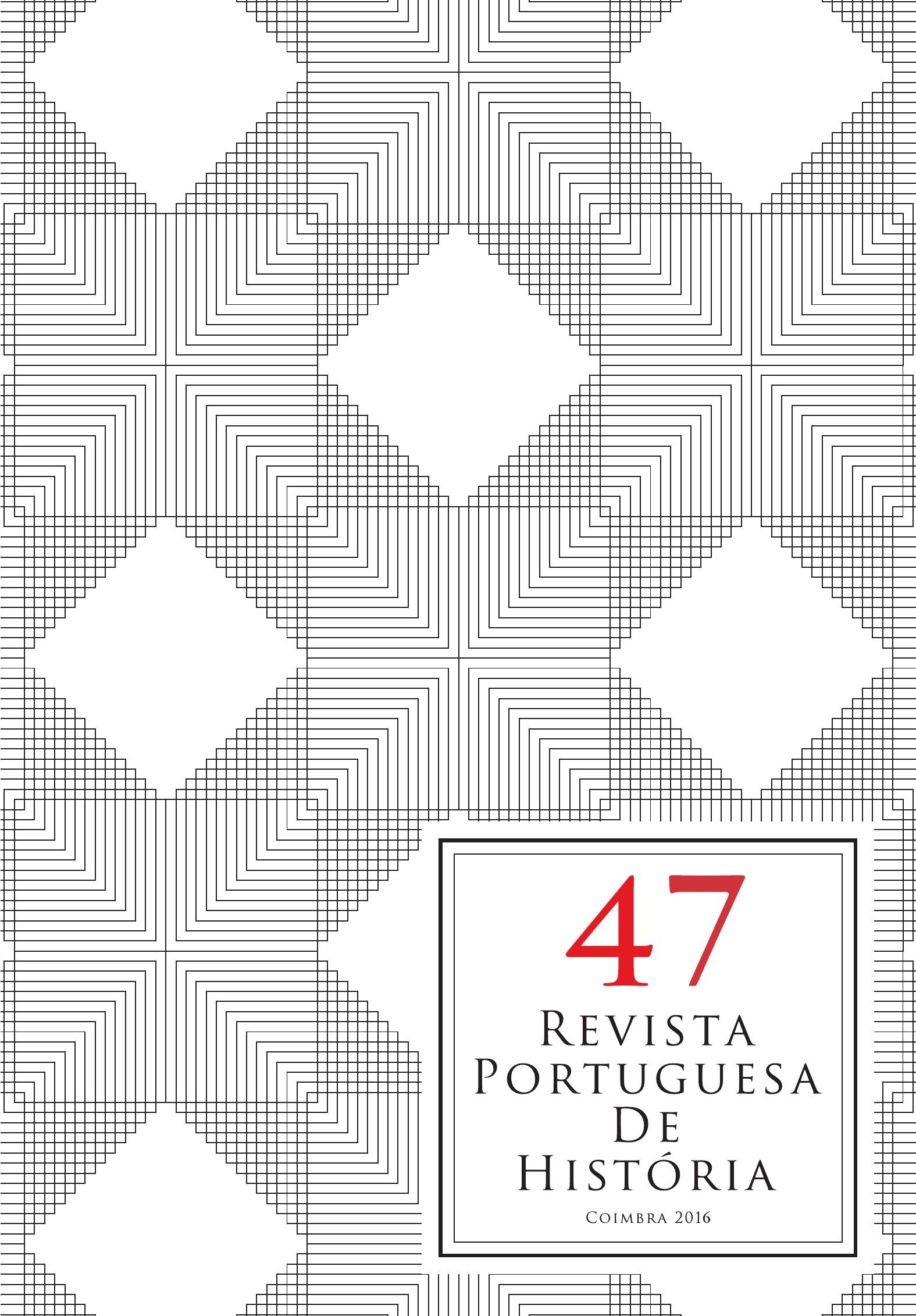




\title{
Em busca da perfeição cristã: práticas espirituais e devotas dos leigos em Portugal (séculos XVI-XVII)
}

\section{In search of Christian perfection: spiritual and devout practices of the laity in Portugal (16th-17th centuries)}

\author{
Paula Almeida Mendes \\ Faculdade de Letras da Universidade do Porto - CITCEM \\ paula_almeida@sapo.pt
}

Texto recebido em/Text submitted on: 31/01/2016

Texto aprovado em/Text approved on: 22/06/2016

\section{Resumo:}

Tendo como pano de fundo a problemática da História da espiritualidade e pretendendo chamar a atenção para a importância das práticas espirituais e devotas entre os leigos, em Portugal, ao longo dos séculos XVI e XVII, este artigo procura estudar, com base em obras de pendor hagiográfico e devoto, alguns casos concretos de figuras imbuídas de preocupações espirituais, que viveram no século, e que se distinguiram no exercício das virtudes cristãs, tendo algumas delas falecido em «odor de santidade».

\section{Palavras-chave:}

Leigos; Espiritualidade; «Vidas» devotas; Séculos XVI-XVII.

\section{Abstract:}

Against the backdrop of the problem of the History of spirituality and intending to draw attention to the importance of the spiritual and devotional practices among the laity, in Portugal, during the 16th and 17th centuries, this article tries to study, based on hagiographic and devout works, some specific cases of figures imbued of spiritual concerns, who lived in the century, and have distinguished themselves in the exercise of Christian virtues, and some of them have died in "odor of sanctity".

Keywords:

Laity; Spirituality; Devout «Lives»; 16 th -17 th centuries. 
A emergência de novos objetos de estudo no campo da História tem permitido equacionar várias e diversas problemáticas e interpretações, pese embora o facto de a ter conduzido à já designada «encruzilhada epistemológica» ${ }^{1}$. Um desses domínios é o da história da vida privada, que, enquanto objeto de interesse historiográfico, só adquire a importância que lhe é reconhecida no século XX, graças aos estudos pioneiros de Philippe Ariès. Efetivamente, a edição dos cinco volumes da Histoire de la Vie Privée, dirigida por Philippe Ariès e Georges Duby $^{2}$, consagrou, definitivamente, o interesse e a pertinência do estudo das problemáticas que se enquadram neste ramo da História, que, necessariamente, deverão ser interpretadas tendo em conta múltiplas perspetivas.

Tal como em todos os ramos da história da cultura, os silêncios e as lacunas das fontes, dos textos, dos documentos, que, em muitos casos, apresentam um caráter fragmentário e/ou difuso, exigem-nos que as hipóteses de interpretação de várias problemáticas históricas e culturais sejam repensadas, obrigando, muitas vezes, a uma transdisciplinaridade, que contribua para a abertura de pistas que permitam «avançar» na construção do saber e do conhecimento da História.

No caso concreto das temáticas às quais é consagrado este volume da Revista Portuguesa de História, que envolvem, necessariamente, questões ligadas às relações familiares, aos afetos, à civilidade, às linhagens - que têm que ser também compreendidas no quadro de sociabilidades e solidariedades várias - estas ficarão mais «iluminadas» se articularmos o estudo destas questões com a história da espiritualidade, nomeadamente no que diz respeito a práticas e representações. Deste modo, tendo em conta o contexto doméstico, em ambiente leigo, em Portugal, durante os séculos XVI e XVII, parecenos pertinente auscultar os moldes em que se inscreveram determinadas vivências dos membros de algumas famílias, realçando, sobretudo, as questões relacionadas com as práticas espirituais e devotas e de que modo condicionam não só comportamentos, atitudes, enfim, os quotidianos, mas também poderão funcionar como um meio para alcançar a «santidade».

Os dados respigados nas fontes consultadas, que se inscrevem, sobretudo, no filão da literatura de espiritualidade e hagiográfica, são escassos. Em regra geral, as informações que considerámos mais pertinentes revelam-nos comportamentos e atitudes, em ambiência doméstica, mais próximos dos meios monásticos ou conventuais do que leigos. Ora, esta focalização não pode, evidentemente, ser dissociada dos propósitos imediatos que nortearam a escrita

\footnotetext{
${ }^{1}$ Ana Leonor P. Dwarkasing, "No rasto de problemas actuais da história", Revista de História das Ideias, 11 (1989), p. 577-639.

${ }^{2}$ Paris, Seuil, 1985-1987.
} 
dessas obras: como é sabido, a multiplicação, sobretudo ao longo do século XVII e da primeira metade do século XVIII, de edições de «Vidas» de santos e devotas, assim como de manuais de confissão, de «espelhos», de artes bene moriendi e de «artes de vida», entre outros textos de tipologia diversa, mas sempre de cariz «normativo» e paradigmático, que assumiu contornos mais acentuados na moldura da ofensiva contrarreformista ${ }^{3}$, materializada em um discurso retórico que tinha como propósito o disciplinamento dos comportamentos dos leitores, ${ }^{4}$ exortando-os à imitação dos modelos exemplares propostos, e a solidificar as suas práticas espirituais e devotas - a frequência dos sacramentos e da oração vocal e mental, o exercício das virtudes, muito especialmente a da caridade, as práticas ascéticas (mortificações, penitências...), a leitura de obras de espiritualidade e de devoção, em articulação com a veiculação dos preceitos cristãos: como sublinhou Maria de Lurdes Correia Fernandes, a reforma que a Igreja foi começando a sofrer, a partir do século XV, que se concretizou na reforma das ordens religiosas, do clero secular e dos rumos da pastoral, estendeu-se também à esfera dos cristãos, por meio de uma estratégia que visava disciplinar e morigerar comportamentos e atitudes, recorrendo à difusão de modelos de perfeição, adaptados aos diferentes «estados»». Neste sentido, os vários casos de leigos, que abrangem todas as camadas da sociedade, divulgados pelas fontes que consultámos, ilustram exemplarmente como é possível uma conciliação entre o exercício das virtudes e das práticas espirituais e devotas e os deveres do seu «estado», garantindo, assim, que cada indivíduo poderia alcançar a perfeição cristã.

Mas valerá a pena sublinhar que a muito significativa evolução que os modelos de santidade foram sofrendo, a partir da Baixa Idade Média, refletiu-se em uma

${ }^{3}$ Maria de Lurdes Correia Fernandes, "Espiritualidade (Época Moderna)", in Carlos Moreira de Azevedo (dir.), Dicionário de História Religiosa de Portugal, vol. II, Lisboa, Círculo de Leitores, 2000, p. 187-193; Zulmira C. Santos, "Literatura religiosa (Época Moderna)", in Dicionário de História Religiosa de Portugal, vol. III, Lisboa, Círculo de Leitores, 2000, p. 125-130.

${ }^{4}$ Marina Caffiero, "Tra modelli di disciplinamento e autonomia soggettiva", in Giulia Barone, Marina Caffiero, Francesco Scorza Barcellona (a cura di), Modelli di santità e modelli di comportamento. Contrasti, intersezioni, complementarità, Torino, Rosenberg \& Sellier, 1994, p. 265-281.

${ }^{5}$ Maria de Lurdes Correia Fernandes, "Da reforma da Igreja à reforma dos cristãos: reformas, pastoral e espiritualidade", in Carlos Moreira de Azevedo (dir.), História Religiosa de Portugal, vol. II, Lisboa, Círculo de Leitores, 2000, p. 15-38; Dilwyn Knox, “«Disciplina»; le origini monastiche e clerical del buon comportamente nell'Europa cattolica del Cinquecento e del primo Seicento", in Paolo Prodi (a cura di), Disciplina dell'anima, disciplina del corpo e disciplina della società tra medioevo es età moderna, Bologna, Il Mulino, 1994, p. 69-99. 
(renovada) perceção daquela e nas próprias vivências e práticas espirituais dos leigos ${ }^{6}$. Efetivamente, ao longo da Idade Média, havia-se difundido a ideia de que a vida «no século» dificilmente era compatível, na prática, com a perfeição cristã ${ }^{7}$ ainda que tivessem surgido recomposições religiosas, políticas e sociais, como, por exemplo, a da problemática da espiritualidade do casamento e da possibilidade de «santificação» dos casados, que foram alterando profundamente as representações de santidade ${ }^{8}$, a verdade é que a espiritualidade daqueles que viviam no século era condicionada pelo forte ascendente do modelo religioso, apesar de se defender que a salvação era algo acessível a todos, independentemente do seu estado. No entanto, foram surgindo «vias» privilegiadas, orientadas para uma emancipação dos leigos, tais como certas confrarias, as ordens terceiras e algumas experiências de reclusão ${ }^{9}$ e de beguinagem ${ }^{10}$, direcionadas para os leigos que buscavam um caminho de perfeição ${ }^{11}$, assim como a influência que a Devotio moderna, surgida na segunda metade do século XIV, exerceu, no sentido da afirmação de uma espiritualidade afetiva e interiorista. Aliás, na Baixa Idade Média, assistiu-se à canonização de alguns leigos, todos eles casados: São Luís, rei de França, Santa Brígida de Suécia, Santa Isabel de Hungria, Santo Élzear de Sabran, barão de Ansouis e conde de Ariano $^{12}$, pertencentes à realeza ou à

\footnotetext{
${ }^{6}$ Para o caso português, veja-se: Maria de Lurdes Rosa, “A religião no século: vivências e devoções dos leigos”, in Ana Maria Jorge, Ana Maria Rodrigues (coord.), História Religiosa de Portugal, vol. I, Lisboa, Círculo de Leitores, 2000, p. 423-508.

${ }^{7}$ André Vauchez, La sainteté en Occident aux derniers siècles du Moyen Âge. D'après les procès de canonisation et les documents hagiographiques, École Française de Rome, 1988, p. 410.

${ }^{8}$ Veja-se, a propósito, André Vauchez, Les laïcs au Moyen Âge. Pratiques et expériences religieuses, Paris, Éditions du Cerf, 1987; Idem, "La santità dei laici nell'Occidente medievale: nascita ed evoluzione di un modelo agiografico (secoli XII-XIII)", in Esperienze religiose nel Medioevo, Roma, Viella, 2003, p. 15-26.

${ }^{9}$ Anna Benvenuti Papi, "Velut in sepulchro: cellane e recluse nella tradizione agiografica italiana", in Sofia Boesch Gajano, Lucia Sebastiani (a cura di), Culto dei santi, istituzioni e classi sociali in età preindustriale, L'Aquila/Roma, Japadre, 1984, p. 367-455.

${ }^{10}$ José Sebastião da Silva Dias, Correntes de sentimento religioso em Portugal, tomo I, Coimbra, 1960, p. 65.

${ }^{11}$ Giulia Barone, "Nuove proposte per nuovi ceti", in Modelli di santità e modelli di comportamento, cit., p. 143-147.

12 Élzear de Sabran foi canonizado em 1369. A sua fama sanctitatis advinha das suas revelações e visões, assim como do seu casamento não consumado, que durou vinte e cinco anos, com Delphine de Puimichel, que foi beatificada em 1694. Sobre estes casados modelares, veja-se: André Vauchez, "Deux laïcs en quête de perfection: Elzéar de Sabran (†1323) et Delphine de Puimichel (†1360)" e "Elzéar et Delphine ou le mariage virginal" in Les laïcs au Moyen Age..., cit., p. 83-92 e 211-224, respectivamente.
} 
aristocracia, e, muito significativamente, um comerciante, Santo Homebon de Cremona ${ }^{13}$.

No entanto, apesar dos vários matizes e recomposições religiosas, políticas e sociais que foram, paulatinamente, alterando as representações de santidade e admitindo a possibilidade de uma «santificação» no contexto da vida secular, a verdade é que, nos séculos XVI e XVII, foram muito poucos os leigos, especialmente casadas e viúvas, cuja fama sanctitatis foi sancionada pela Cúria romana, permitindo a sua subida aos altares ${ }^{14}$.

Tendo em conta este quadro, parece-nos importante chamar a atenção para os diálogos e a inter-relação da vida devota com certos aspetos relacionados com a vida doméstica, social e moral no universo dos leigos. Desde logo, importa notar que os dois «estados» contemplados, o celibato e o casamento, são condicionados por aspetos que acabam por configurar a sua identidade. Mas, obviamente, teremos que ter em conta a questão do género e em que medida este acaba por se articular com a questão do «estado». Comecemos pelo género feminino.

$\mathrm{O}$ discurso em torno das mulheres oscilou, frequentemente, entre dois polos, que, como é sabido, assumem um destaque significativo no contexto da «Querelle des Femmes»: o louvor e a crítica negativa.

No quadro da exaltação da figura feminina e da defesa do valor e das virtudes tradicionalmente a ela associadas e do reconhecimento das suas competências, claramente oposto àquele que se pautava pelos acérrimos ataques (ainda que, por vezes, tópicos) que vários textos de cariz misógino vinham divulgando, sobretudo, a partir de finais da Idade Média, a obra De Claris Mulieribus (1374), de Giovanni Boccaccio, dará um contributo fundamental para a afirmação de um filão literário pró-feminista, claramente exaltador das «claras e ilustres mulheres», sustentado por catálogos ou galerias de «mulheres ilustres». Com efeito, a pioneira obra de Boccaccio influenciará a escrita de outras obras que se inscrevem nessa linha, sobretudo a partir da segunda metade do século XVI, obras essas cuja produção e focalização eram já sintomáticas de novas tónicas e contornos, característicos dos tempos pós-Trento, que valorizam, sobretudo, os exemplos de mulheres «insignes em virtude», destacando o conjunto das mártires e das virgens, enquanto paradigmas que, desde o cristianismo primitivo,

${ }^{13}$ André Vauchez, "Le «trafiquant céleste»: Saint Homebon de Crémone (†1197), marchand et «père des pauvres»", in H. Dubois, Jean-Claude Hocquet, André Vauchez (ed.), Horizons marins, itinéraires spirituels ( $V^{e}$-XVIII ${ }^{e}$ siècles), I vol., Publications de la Sorbonne, 1987, p. 115-122.

${ }^{14}$ Cf. Giulia Barone, "La canonizzazione di Francesca Romana (1608): la reproposta di un modelo agiografico medievale", in Gabriella Zarri (a cura di), Finzione e Santità tra medioevo ed età moderna, Torino, Rosenberg et Sellier, 1991, p. 264-279. 
vinham constituindo os «modelos por excelência» de santidade feminina. Assim, se compreenderá a progressiva valorização, em obras de contornos hagiográficos, de mulheres que permaneceram celibatárias ao longo de toda a sua vida. Comecemos pelo caso da infanta D. Maria (1521-1577), filha de D. Manuel I e de sua terceira mulher, D. Leonor de Habsburgo. A vida desta infanta portuguesa pode ser conhecida, mais largamente, através da Vida de la serenissima infanta D. Maria, hija delrey D. Manuel, fundadora de la insigne capilla de Nuestra Señora de la Luz (1675) ${ }^{15}$, de Fr. Miguel Pacheco (O. Cristo); todavia, autores como João de Barros, no Panegírico à muy alta e esclarecida Princeza Infanta D. Maria nossa senhora ${ }^{16}$ - texto claramente encomiástico -, Duarte Nunes de Leão, na Descrição do Reino de Portugal ${ }^{17}$ (1610) - obra que faz eco de uma certa defesa ou exaltação do reino, produzida no contexto da Monarquia Dual -, ou Fr. Luís dos Anjos, no seu Jardim de Portugal (1626) ${ }^{18}$, que recolhe e celebra a memória de várias portuguesas «ilustres em virtude», legaram-nos breves retratos da infanta, exaltando, em especial, as suas virtudes, «ciência» e gosto pelas artes e letras; de facto, pese embora o facto de a escrita de cada uma destas obra ter sido norteada por propósitos diferentes, parecenos, no entanto, que, cada uma a seu modo, realça uma certa conciliação entre a vida ativa e a vida contemplativa de D. Maria; de resto, Fr. Miguel Pacheco conta-nos que o paço da infanta «parecia más un colegio de virtudes, ciencias y artes, que aula de una Princesa seglar» ${ }^{19}$.

D. Carolina Michaëlis de Vasconcelos, no seu clássico estudo A Infanta D. Maria de Portugal (1521-1577) e as suas damas ${ }^{20}$, utilizou o epíteto «A Sempre Noiva» para se referir à figura da infanta D. Maria, realçando, assim, o papel de joguete que esta desempenhou no xadrez político da época: efetivamente, apesar de se terem estipulado vários contratos com vista ao casamento da infanta D. Maria, tal nunca se chegou a concretizar: com efeito, Fr. Miguel Pacheco afirma que D. Maria pretendia «perseverar hasta la muerte en el estado de doncella» $\aleph^{21}$, atitude que a aproximava do modelo das virgens que, como já foi

${ }^{15}$ Lisboa, por João da Costa.

${ }^{16}$ Utilizamos a seguinte edição: João de Barros, Panegíricos: panegírico de D. João III e da Infanta D. Maria, Lisboa, Sá da Costa, 1937.

${ }^{17}$ Utilizamos a seguinte edição: Duarte Nunes de Leão, Descrição do Reino de Portugal, Lisboa, Universidade de Lisboa/Faculdade de Letras/Centro de História, 2002.

${ }^{18}$ Utilizamos a seguinte edição: Fr. Luís dos Anjos (O.E.S.A), Jardim de Portugal (ed. de Maria de Lurdes Correia Fernandes) Porto, Campo das Letras, 1999.

${ }^{19}$ Fr. Miguel Pacheco, Vida de la serenissima infanta D. Maria ..., cit..

${ }^{20}$ Lisboa, BN, 1983.

${ }^{21}$ Cf. Fr. Miguel Pacheco, Vida de la serenissima infanta D. Maria ..., cit., f. 56 v. 
realçado em alguns estudos, era, por esta época, proposto como paradigma de comportamento a senhoras da realeza e da alta nobreza, que, em muitos casos, eram mesmo casadas ${ }^{22} \ldots$ Neste sentido, de acordo com o biógrafo, as práticas quotidianas e espirituais ou devotas da infanta revelam a influência do modelo de raiz monástica, refletindo, deste modo, a perenidade deste paradigma enquanto modelo de excelência para o género feminino, como revela estre trecho: «a sus horas se ponía a la mesa, con la grandeza debida a su real persona, mas en el comer com la templança de religiosa observantissima; y entre tanta abundancia de manjares sazonados, muchas vezes ayunaba nuestra Princesa, dexando de tocar en muchos por abstinencia como otros por necessidad ${{ }^{23}}^{23}$ Neste sentido, Fr. Miguel Pacheco afirma mesmo que «este tenor de vida igualaua a la Religion mas reformada, viuiendo en el mundo como se estuuiera fuera del $\gg^{24}$, envolvendo, assim, a figura da infanta D. Maria, ainda que leiga, em uma aura de «santidade».

Centremo-nos agora no caso de D. Leonor de Noronha. Nascida, ao que parece, em Évora, em 1488, D. Leonor de Noronha era filha de D. Fernando de Meneses, segundo marquês de Vila Real, e de D. Maria Freire e irmã de D. Pedro de Meneses, futuro terceiro marquês de Vila Real e segundo conde de Alcoutim. Sobre a vida de D. Leonor, chegaram-nos algumas breves «notícias»: nas fontes editadas no século XVII, a «Vida» que Fr. Luís dos Anjos (O.E.S.A.) incluiu no seu Jardim de Portugal (1626) ${ }^{25}$ e a que Jorge Cardoso registou no I tomo do seu monumental Agiologio Lusitano (1652), fazendo dela memória a 17 de Fevereiro; entre fontes publicadas no século XVIII, a breve «Vida» que Damião de Froes Perim incluiu no segundo tomo do seu Theatro Heroino, abecedário histórico e catálogo de mulheres ilustres em armas, letras, acções heroicas e artes literárias $^{26}$. Não deixa de ser significativo que Fr. Luís dos Anjos e Jorge Cardoso tenham contemplado, nas suas compilações hagiográficas, a «Vida» de D. Leonor de Noronha, tendo em conta que deixaram esquecidos os casos de mulheres que se notabilizaram nas armas e nas letras: mas o exemplo de D. Leonor, assim como o da infanta $\mathrm{D}$. Maria, também registado nestes florilégios, parecem ter sido «aproveitados» por estes dois autores porque estas, além das letras, também se distinguiram pela «virtude», nomeadamente na frequência dos sacramentos e na prática das devoções: e parece ter sido esta «resistência»

${ }^{22}$ Cécile Vincent-Cassy, Les Saintes Vierges et Martyres dans l'Espagne du XVII siècle. Culte et Image, Madrid, Casa de Velásquez, 2011.

${ }^{23}$ Cf. Fr. Miguel Pacheco, Vida de la serenissima infanta D. Maria, ...cit., f. 98 r.

${ }^{24}$ Fr. Miguel Pacheco, Vida de la serenissima infanta D. Maria, ... cit., f. 99 r.

${ }^{25}$ Fr. Luís dos Anjos, Jardim de Portugal, cit., p. 243-244.

${ }^{26}$ Lisboa, na Regia Officina Sylviana e da Academia Real, 1740, p. 21-22. 
a incluir os exemplos de mulheres «ilustres em letras» e «em armas» que votou ao esquecimento, até ao século XVIII, os casos de senhoras como Joana Vaz, Paula Vicente ou Públia Hortênsia de Castro... Em todo o caso, o cultivo das «boas letras» parece ser uma extensão da faceta espiritual e devota de D. Leonor de Noronha.

Se atendermos à breve «notícia» que nos legou Fr. Luís dos Anjos no Jardim de Portugal, D. Leonor é apresentada, logo nas linhas iniciais, como uma imitadora da Virgem Maria: com efeito, o agostiniano louva o seu recolhimento, tão semelhante ao da Virgem Maria - uma das virtudes «especificamente» femininas, na medida em que «nas mulheres é princípio de todo bem». D. Leonor «estava de ordinário escondida em seu oratório, ora lendo, ora orando, ora escrevendo, donde veio a ser em nosso reino mui ilustre em virtudes e juntamente mui sábia; donde, como Proba Faltonia tem lugar entre os antigos escritores da Igreja notados por Santo Isidoro» ${ }^{27}$.

De acordo com Diogo Barbosa Machado, D. Leonor «meditava com excessiva ternura de dia, e de noute os tormentos que o Redemptor do mundo padecera em satisfação da culpa do primeiro homem oferecendo as lagrimas que continuamente distilavão os seus olhos em retribuição do precioso sangue, que derramou o Verbo Divino ${ }^{28}$.

Uma outra senhora, D. Isabel de Sousa (f. 22 de Junho de 1518) ${ }^{29}$, que foi camareira-mor da infanta D. Isabel de Castela, filha dos Reis Católicos ${ }^{30}$, distinguiu-se também no exercício das virtudes cristãs. Após o falecimento da infanta, em 1498, como consequência do parto do príncipe D. Miguel da Paz, recolheu-se «às suas casas da Alcaçoua, de que el Rei D. Ioão II lhe tinha feito doação», onde passou «o restante em vida celibata, com mostras de honesta, \& virtuosa donzela, frequentando deuota os Sacramentos, vizitando descalça os Templos, \& assistindo piedosa aos enfermos, condoendose sempre dos trabalhos alheios, como proprios. A que juntaua recitar de joelhos todos dias o diuino Officio, \& ouuir Missa com estranha deuoção» ${ }^{31}$. O tempo que lhe restava destas piedosas atividades era gasto na oração e leitura de livros

${ }^{27}$ Fr. Luís dos Anjos, Jardim de Portugal, cit., p. 244.

${ }^{28}$ Diogo Barbosa Machado, Bibliotheca Lusitana, tomo III, Coimbra, Atlântida, 1966, p. 13.

${ }^{29}$ D. Isabel de Sousa era filha de João Gomes da Silva e de D. Branca de Sousa.

${ }^{30}$ A infanta D. Isabel de Castela (1470-1498) casou, em primeiras núpcias, com o príncipe D. Afonso, filho único de D. João II e de D. Leonor de Lencastre. Após a morte de D. Afonso, em 13 de Julho de 1491, em sequência de uma queda de cavalo, D. Isabel casaria, em 1497, com D. Manuel I.

${ }^{31}$ Jorge Cardoso, Agiologio Lusitano dos Santos, \& Varoens ilustres em virtude do Reyno de Portugal, \& suas Conquistas, tomo III, Lisboa, por Pedro Craesbeeck, 1666, p. 780. 
espirituais ${ }^{32}$. Deste modo, o acento colocado por Jorge Cardoso nas «virtudes» e nas práticas espirituais e devotas de D. Isabel de Sousa, sublinhando a sua excecionalidade - claramente em sintonia com o ideal de «heroicidade» que vinha sendo tão valorizado por esta época - está escorado, sobretudo, no modelo hagiográfico das virgens.

No conjunto das «Vidas» devotas consultadas, encontramos também, curiosamente, relatos sobre figuras de condição humilde, tal como Melícia Fernandes, que foi filha espiritual de Fr. Luís de Granada e ama de uma senhora nobre, D. Cecília de Mendonça, que foi comendadeira de Santos, e que faleceu em «odor de santidade». O caso de Melícia Fernandes encontra-se, claramente, escorado no modelo de uma santa de condição humilde, a saber, o de S. Zita $(† 1278)$, uma empregada doméstica ${ }^{33}$.

A partir dos relatos que nos legaram Fr. Luís de Granada e Jorge Cardoso, parece-nos possível traçar um retrato desta mulher, destacando a sua faceta espiritual e devota. Melícia Fernandes tinha a seu cargo «o gouerno, \& prouisão da casa, resplandecia em todo genero de virtudes. A ordem que guardaua era á prima noite prouerse do necessario para o seguinte dia; no qual madrugaua a orar, \& comungar na Igreja, onde perseueraua immouel atè se acabarem as Missas». ${ }^{34}$ Quando regressava a casa, «compria co as obrigações do officio; \& os spacios, que lhe vagauão entre dia» recolhia-se no oratório ${ }^{35}$, onde lhe era tam fácil leuantar o spiritu a Deos, que muitas vezes ficaua arrobada dos sentidos, com tal secreto nos oráculos, \& documentos, que interiormente recebia da diuina liberalidade, que parecia ter em seu coração aquellas palavras do Profeta Isaias: Secretum meum Mihi〉. Milícia Fernandes destacou-se no exercício das virtudes, muito especialmente na sua «mansidão», pois «lidando oito anos com o trafego d'aquella casa, soportando cada hora injuriosas palavras, \& repostadas dos mal contentes seruos, nunqua ja mais se alterou, antes co a facie rizonha dizia: Seja por amor de Deos» ${ }^{36}$.

No caso concreto das «Vidas» de casadas, mas também de viúvas, é possível discernir uma progressiva valorização daqueles estados e da sua faceta ativa, no âmbito da capacidade de gestão da vida doméstica, e, sobretudo, de educar

${ }^{32}$ Jorge Cardoso, Agiologio Lusitano ..., cit., tomo III, p. 781.

${ }^{33}$ Raffaella Sarti, "Zita, serva e santa. Un modelo da imitare?”, in Modelli di Santità ..., cit., p. 307-359.

${ }^{34}$ Jorge Cardoso, Agiologio Lusitano ..., cit., tomo II, p. 70.

${ }^{35}$ Sobre a importância do oratório enquanto espaço de devoção privada, cf. José Adriano de Freitas Carvalho, "Um espaço de oração na Época Moderna. O oratório particular: os usos. E também os abusos?", Via Spiritus, 7 (2000), p. 145-162.

${ }^{36}$ Jorge Cardoso, Agiologio Lusitano ..., cit., tomo II, p.70-71. 
cristãmente os filhos ${ }^{37}$, que tornará possível o reconhecimento de uma imagem de santidade feminina compatível com a condição laical. Neste sentido, como sublinhou Marina Caffiero, constitui uma renovada visão da condição leiga feminina enquanto via autónoma de acesso à santidade, refletindo, por sua vez, a valorização do papel desempenhado pela mulher no seio da família moderna, e, deste modo, preparando a via que culminará com a exaltação da figura da «mãe de família», já no século XIX ${ }^{38}$.

Como realçou Maria de Lurdes Correia Fernandes, a tradição biográfica e, em geral, a hagiográfica, não contavam com muitos exemplos de «perfeitas casadas» que pudessem facilmente ser incluídas entre os modelos de santidade propostos às mulheres ${ }^{39}$. De facto, como sublinhou a mesma autora, os modelos de santidade feminina mais valorizados e propostos à imitação foram sempre os das virgens, sobretudo mártires e religiosas: entre as casadas, existiram, contudo, alguns casos que obtiveram um notório reconhecimento, em muitos casos pela Santa Sé, mas cingiam-se aos exemplos daquelas que, embora obrigadas à contingência do seu estado, «puderam seguir a via da castidade conjugal, ou das que só o vieram a ser depois de enviuvarem ou de, por motivos diversos, se separaram dos maridos e abraçaram a vida religiosa ${ }^{40}$, na linha dos paradigmas propostos por São Jerónimo, em muitas das suas cartas ${ }^{41}$.

Neste sentido, valerá a pena evocar o caso de D. Elvira de Mendonça, mulher de D. Fernão Martins Mascarenhas ${ }^{42}$, cuja «Vida» foi redigida por Fr. Luís de

${ }^{37}$ Maria de Lurdes Correia Fernandes, Espelhos, Cartas e Guias..., cit.., esp. cap. V: «A educação dos filhos», p. 163-198, e cap. X: «O primado dos "bons costumes" na educação dos filhos», p. 339-402.

${ }^{38}$ Marina Caffiero - «Tra modelli di disciplinamento e autonomia soggetiva», cit., p. 270.

${ }^{39}$ Maria de Lurdes Correia Fernandes, "Uma clarissa ilustre do século XVI: Ana Ponce de Leon, condessa de Feria e monja de Santa Clara de Montilla", in Las clarisas en España y Portugal. Actas del Congreso Internacional (Salamanca, 20-25 de septiembre de 1993), Salamanca, s/d, p. 335.

${ }^{40}$ Maria de Lurdes Correia Fernandes, "Uma clarissa ilustre do século XVI...", cit., p. 335; Idem, "Viúvas ideais, viúvas reais. Modelos comportamentais e solidão feminina (séculos XVI-XVII)", Faces de Eva, no 1-2 (1999), p. 51-86.

${ }^{41}$ Maria de Lurdes Correia Fernandes, "Uma clarissa ilustre do século XVI...", cit., p. 335.

${ }^{42}$ D. Elvira de Mendonça era filha de D. João de Alarcão, caçador-mor de D. João III, e de sua mulher, D. Margarida Soares. Casou com D. Fernão Martins Mascarenhas (filho de D. João Mascarenhas e de D. Margarida ou D. Leonor, filha de D. Vasco Coutinho, conde de Borba, e de D. Catarina da Silva), capitão de ginetes, comendador de Mértola e embaixador no Concílio de Trento. Faleceu s.g. (cf. Manuel José da Costa Felgueiras Gayo, Nobiliário de Famílias de Portugal, vol. XVII, Edição de Carvalhos de Basto, Braga, 1939, p. 9, e vol. XVIII, p. 80). 
Granada $^{43}$. O comportamento moral e social de D. Elvira de Mendonça era, de resto, o preceituado pelas obras que entroncavam no filão de literatura de moralidade da época: depois de casada, entregou-se «cuanto á la condición de su estado le era posible, á los ejercicios de la oración», «para la cual á imitación del profeta Daniel tenía tres tempos deputados (...) uno en la mañana, y outro después de comer, mientras su marido reposaba, y outro en la noche después de cerradas las puertas y recogido su gente. Porque en este tiempo, assentada á los pies de la cama de su marido y vuelto el rostro á unas iglesias que tenía delante, en las cuales estaba el Santo Sacramento, gastaba ordinariamente cuatro horas en oración, en la cual era tan grande la alegría espiritual que su ánima recebía», que dizia, algumas vezes, «que así se estuviera hasta la mañana, sino fuera por detener tanto una servidora que la guardaba á acostar. Y ni por huéspedes que tuviese, ni otras ocasiones, jamás perdia este su ordinario ejercicio de la oración» ${ }^{44}$; «vivía como las otras señoras de su calidad, muy amiga de su marido $»^{45}$; lia $«$ libros de buena doctrina $»^{46}$; amava Deus sobre todas as coisas, desapegando-se mesmo dos laços de parentesco ${ }^{47}$; distinguiu-se na prática das virtudes da abstinência ${ }^{48}$, da penitência ${ }^{49}$, da pobreza $^{50}$, da caridade ${ }^{51}$, da

${ }^{43}$ Fr. Luís de Granada, Vida de la muy ilustre señora Doña Elvira de Mendoza, in Obras de Fr. Luis de Granada de la Orden de Santo Domingo, edición critica y completa por Fr. Justo Cuervo, tomo XIV, Imprenta de la Viuda y Hija de Gómez Fuentenebro, Madrid, 1906, p. 411-422.

${ }^{44}$ Fr. Luís de Granada, Vida de la muy ilustre señora Doña Elvira de Mendoza..., cit., p. 413-414.

${ }^{45}$ Fr. Luís de Granada, Vida de la muy ilustre señora Doña Elvira de Mendoza ..., cit., p. 412.

${ }^{46}$ Fr. Luís de Granada, Vida de la muy ilustre señora Doña Elvira de Mendoza ..., cit., p. 412.

${ }^{47}$ Fr. Luís de Granada, Vida de la muy ilustre señora Doña Elvira de Mendoza..., cit., p. 417-418.

48 «Por lo cual buscó esta señora en su estado manera cómo ser tan extremada en esta virtud de la abstinencia como lo era en su compañera la oración. Porque primeiramente su comer era muy poco (...). Outra cosa diré, que supe de su boca, que parecerá increíble, mas pongo á nuestro Señor por testigo que la supe della. Dijome pues que habiendo ordinariamente en la mesa de su marido perdices ó cosa de aves, nunca esta señora metió en su boca un bocado de cosa que tuviese pluma» (Fr. Luís de Granada, Vida de la muy ilustre señora Doña Elvira de Mendoza..., cit., p. 415).

${ }^{49}$ «(...) y no sólo com la abstinencia, sino con todas asperezas que podía, mortificaba su carne y correspondia á lo que el amor de Dios le pedia, que era padecer trabajos por Él. Porque traía como outra Judit un áspero cilicio de día, y quitábaselo de noche. Y el cilicio era tan áspero, que vino á causarle una grave enfermedad en las caderas» (ibidem, p. 416).

${ }^{50}$ «Y acordándose también de la pobreza de Cristo y de la desnudez y desabrigo que padeció en el pesebre y en la cruz, quitábase ella en tiempo de invierno el manteo que suelen traer las mujeres debajo de la saya, para padecer frio por amor de Dios» (ibidem, p. 416).

${ }^{51}$ Conta-nos Fr. Luís de Granada que D. Elvira, «entre otros actos de caridad tenía grandes deseos de derramar su sangre y padecer martirio por la gloria de nuestro Señor y porque no 
humildade $^{52}$ e da honestidade ${ }^{53}$. Após a morte do marido, D. Elvira de Mendonça acabaria por se recolher no mosteiro de Montemor, onde permaneceria até ao final da sua vida ${ }^{54}$.

Valerá a pena evocar também o caso da venerável matrona Margarida de Chaves (falecida a 8 de Setembro de 1575), cuja «Vida», intitulada A Margarita animada, idea moral, politica e historica de tres estados, discursada na vida da veneravel Margarida de Chaves, natural da cidade de Ponte Delgada na ilha de S. Miguel (1723), foi escrita por um descendente seu, Francisco Afonso de Chaves e Melo. Desde a infância, «jejuava sete dias continuos, [...] antes da Paschoa do Espirito Santo; \& cada dia, postos os joelhos em terra por sete vezes com huma luz acesa nas mãos, rezava por cada hũa sete Padres nossos, $\&$ sete Ave Marias em seu louvor» ${ }^{55}$. O estado de casada não a impediu de, quotidianamente, praticar exercícios espirituais e devotos, sem descurar as obrigações do seu estado: «Na creação dos filhos todo o seu disvelo se cifrava em instruir no caminho da virtude [...]. Frequentava os Sacramentos da Penitencia, \& Sagrada Cõmunhão só quatro vezes no anno [...] Todo o seu cuydado se empregava em ouvir ler as vidas dos Santos, $\&$ acudir ao remedio dos necessitados $\rangle^{56}$.

$\mathrm{O}$ autor, sem excluir ou desvalorizar os tempos de casada e de «mãe de famílias» de Margarida de Chaves, concede, efetivamente, uma larga atenção ao período em que a «venerável matrona» estava já viúva, a qual, na linha da imitatio Christi, «abnegou-se de si mesma, abraçou a Cruz da penitencia, \& seguiu a Christo com amor, \& ardente caridade, repartindo-a para com Deos, \&

hubiese en el mundo luteranos y herejes que le ofendiesen (ibidem, p. 417). Por outro lado, «sus limosnas eran tan comunes, que su despensa estaba abierta para todos los pobres y necesitados» (ibidem, p. 419).

52 «Esta virtud tenía tan arraigada en su corazón, que muchas veces me decía que no hallaba con quién compararse sino con el mismo demonio. (...) Y por esta misma humildad jamás mandó llevar á la iglesia alcatifa ó almohada, ni aun una esterilla, sino sobre la tierra desnuda estaba de rodillas ó postrada» (ibidem, p. 419).

${ }^{53}$ «Era también esta señora muy amiga de la honestidad de las mujeres y tan enemiga de las que bebían vino, que obligándola los médicos en una grave enfermedad á que bebiese un poquito de vino, por la flaqueza de su estómago, nunca se pudo acabar con ella, porque entre otras virtudes suyas era muy constante en todo lo que según Dios determinaba, como persona que no era cana liviana que se mueve á todo viento» (ibidem, p. 420).

${ }^{54}$ Ibidem, p. 420-421.

${ }^{55}$ Francisco Afonso de Chaves e Melo, A Margarita animada, idea moral, politica e historica de tres estados, discursada na vida da veneravel Margarida de Chaves, natural da cidade de Ponte Delgada na ilha de S. Miguel, Lisboa, Antonio Pedroso Galrão, 1723, p. 26.

${ }^{56}$ Francisco Afonso de Chaves e Melo, A Margarita animada ..., cit., p. 60-61. 
para com o próximo ${ }^{57}$. Tal como recomendava e exigia a literatura da época, as práticas espirituais de Margarida de Chaves eram acompanhadas por aspérrimas e rigorosas penitências e mortificações: deste modo, o biógrafo elogia o facto de aquela se ter cingido com um áspero cilicio «de cabelos de boy, \& com huma tunica de burel, \& outras vezes com hũa de aspero liteyro» ${ }^{58}$, pondo, assim, de parte as tópicas e criticadas «vaidades» femininas ${ }^{59}$; dormiu, durante doze anos «contínuos» «sobre humas taboas, com hum páo por cabeceyra, por se julgar indigna de se deitar em cama. Cahindo por muytas vezes nas ruas entre lodos, se demorava algum espaço, sem se levantar, por mortificação do pejo»; durante todo o ano não comia carne, «por ser só peyxe o seu sustento, \& este era cosido, ou assado muytos dias antes, para ter perdido o gosto, \& sabor»; alimentava-se com ervas e «quando se estendia a mais iguarias, eraõ estas hum figo, ou quatro bagos de uvas»; durante doze anos, teve por cama umas tábuas e um pau por cabeceira, e, no fim da vida, «descansava a cabeça sobre os sapatos» ${ }^{60}$. Com efeito, se é verdade que estas penitências e práticas mortificatórias, tal como o exigia a literatura da época, sustentavam a «ortodoxia» de Margarida de Chaves, em um período em que pairavam suspeitas de «falsa santidade» sobre certas figuras (sobretudo beatas), devido aos seus «acessos extraordinários» ou «arroubos» místicos, que, como é sabido, vinham mantendo a Inquisição atenta e vigilante, teremos também que ter em conta que aquelas não podem ser dissociadas de um certo gosto que a sociedade nutria pelo «maravilhosismo» e pela espetacularidade - tendência esta que se acentuará ao longo do Barroco -, que, em muitos casos, na impossibilidade de se padecer o martírio, funcionavam como uma via alternativa ${ }^{61}$.

${ }^{57}$ Francisco Afonso de Chaves e Melo, A Margarita animada ..., cit., p. 72.

${ }^{58}$ Conta-nos o biógrafo que Margarida de Chaves sempre ocultou estes instrumentos de penitência, de tal modo que uns meses antes de sua morte «os lançou em huma ardente fornalha, para que de nenhũ fossem vistos» (A Margarita animada ..., cit., p. 80-81).

${ }^{59}$ Críticas essas de que fez eco Fr. Antonio Marqués (O.S.A.), Afeite y Mundo Mujeril (1617). Utilizamos a edição de Fernando Rubio (O.S.A.), Barcelona, Juan Flors, 1964.

${ }^{60}$ Francisco Afonso de Chaves e Melo, A Margarita animada ..., cit., p. 80-81; 83.

${ }^{61}$ Jacques Le Brun, "Mutations de la notion de martyre au XVII ${ }^{\mathrm{e}}$ siècle d'après les biographies spirituelles féminines", in Jacques Marx (ed.), Sainteté et martyre dans les religions du livre, Bruxelles, Éditions de l'Université de Bruxelles, 1989, p. 77-90. Neste sentido, valerá a pena lembrar o caso de D. Antónia Margarida de Castelo Branco, que, na sua Autobiografia, evoca alguns episódios da sua vida conjugal, nomeadamente certas situações em que esta foi alvo da violência exercida pelo marido, Brás Teles de Meneses e Faro: todavia, ao invés de se lamentar, aquela sofre resignadamente este sofrimento, interpretando-o como algo motivado por «inspiração divina». Cf. Antónia Margarida de Castelo Branco, Autobiografia (1652-1717) (prefácio e transcrição de João Palma-Ferreira), Lisboa, Imprensa Nacional-Casa da Moeda, 1983. 
Por sua vez, Maria das Neves (falecida em 1662) «gastaua logo a menhãa toda na Igreja [do convento franciscano de Santa Cristina, no bispado de Coimbra) (de que foi insigne bemfeitora) assistindo às Missas, \& Officios diuinos, com muita deuoção, \& com a mesma cõmumgaua a miudo, não faltando por isso aos jejuns, abstinências, cilicios, \& disciplinas de cada dia. As noites vellaua em Oração, \& meditação, a que juntaua algũas deuoções a particulares Sanctos, que tinha tomado por auogados, \& intercessores, para com Magestade diuina. Não sabia estar ociosa, tendo criadas para a descançar, tomaua sobre si o maior trabalho da casa $\rangle^{62}$.

Valerá a pena evocar o caso de uma D. Brites Catarina de Abreu (†1687), cuja «Vida», escrita por seu tio, D. Fernando da Cruz e editada com o título Thezouro escondido: D. Brites Catherina de Abreu, seus colloquios amorozos com Deos; breve noticia de suas virtudes (1689) $)^{63}$, realça as qualidades espirituais e as virtudes desta senhora, ou, para usar a terminologia do biógrafo, a sua «santa vida» e «santa morte». Contudo, o biógrafo não deixou de dar um importante destaque à vida secular e matrimonial de $\mathrm{D}$. Brites Catarina de Abreu, pintando-nos um retrato, ainda que extremamente sucinto, daquilo a que vários textos da época chamavam a «perfeita casada» e que também poderia servir de espelho para outras casadas. Assim, conta-nos D. Fernando da Cruz que D. Brites era «muito alegre, \& engraçada, \& com a muita affabilidade, com que tratava a todos, se fazia amar de todos, os que a conheciam, \& pela sua muita humildade a respeitavam sem comparação mais, do que se uzasse dos faustos, \& grandesas, que usão nesta Corte, as senhoras de sua qualidade; vestia sempre o habito de terceira de São Francisco: fazendo-lhe seu marido Bernardo Sanches Pereira, nisto o gosto em o consentir, porque a amava muito, $\&$ como fidalgo taõ entendido, conhecia suas grandes prendas para a respeitar» ${ }^{64}$, mostrando-nos, deste modo, que as mulheres que abdicavam das «vaidades», mesmo quando estas eram, em razão da sua condição social, toleráveis, eram particularmente elogiadas.

Embora tivesse casado quando ainda era muito jovem, D. Brites Catarina de Abreu, «no governo de sua familia (que era muita)», «mostrou o ser molher forte, sabia, \& prudente, sem necessitar de estímulos, que a obrigassem a acodir ás suas obrigações, porque era notavelmente esperta, \& viva», tendo comunicado várias coisas sobre o governo de sua casa a seu tio, que dizia ser «esta Senhora verdadeiramente a honra das molheres cazadas» e lhes poderia servir de exemplo

\footnotetext{
${ }^{62}$ Jorge Cardoso, Agiologio Lusitano ..., cit., tomo III, p. 232.

${ }^{63}$ Lisboa, por Domingos Carneiro.

${ }^{64}$ D. Fernando da Cruz, Thesouro escondido..., cit., «Carta do confessor desta serva de Deos».
} 
a todas, «ou seja na sogeição a seu marido, ou na vigilancia de sua familia, em occupalla bem, em provella do necessario com abundancia, por ser liberal, \& grandiosa: em ensinarlhe a doutrina, para o que tinha particular graça, \& paciencia: hũa vez lhe succedeo em hum dia de festa, deixar o sermaõ, \& ir a caza, porque lhe lembrou, ficava nella hum menino sem Missa; não fiando esta diligencia de ninguem pelo muito que pesava a observancia da Ley de Deos ${ }^{65}$.

No quadro das suas práticas espirituais e devotas, o biógrafo realça o seu exercício da oração, constituída por «amorosas meditações, principalmente de Christo Jesu nosso bem, crucificado, o qual Senhor trouxe muitos tempos muy vivamẽte na imaginação representado», tendo por isso composto muitos colóquios, «pelos quaes desabafava do amoroso incendio, que ardia em seu coração, não os fundando em delicados conceitos, mas em enternecidos affectos; nem tão pouco se enfastiava de repetir muitas vezes as mesmas palavras, como os Serafins do Ceo, que se não canção de alternar continuamente Sanctus, Sanctus, Sanctus; \& deste modo veyo a ser a sua oração quasi continua; \& muito poucas pessoas se acharáõ, que assi saibaõ (com a graça de Deos) ajuntar as duas vidas, contemplativa, \& activa, como esta sua serva, que não faltando ás obrigações de seu estado, gozasse dos amorosos abraços do Divino Esposo, de quem recebia muitos favores», o quotidiano recebimento do Santíssimo Sacramento, a sua caridade - de tal modo que era commumente chamada a «mãe dos pobres» - e as suas mortificações, as quais «apontava em hum livro, com hũas cifras, antes das quaes punha o Santissimo Nome de Jesus; dizendo que assi na arismética as cifras não tem por si valia algũa, assi as nossas obras saõ de nenhum valor sem Jesus; assi para a graça, como para a gloria», cujo título era «Grinalda de flores, colhidas no jardim da mortificação, para apresentar á Mãy de Deos na hora da morte $»^{66}$.

Com efeito, os casos evocados parecem constituir um quase decalque de modelos de «santas viúvas» anteriores, nomeadamente de Santa Paula e de Santa Mónica, que se assumiam como exemplos passíveis de renovadas imitações ${ }^{67}$.

Nas fontes consultadas, recolhemos igualmente alguns casos de casados que, tendo em conta vários aspetos da sua vida moral e espiritual, personificavam modelarmente um ideal de «perfeitos casados», para utilizamos a designação proposta por Maria de Lurdes Correia Fernandes, tão valorizado nos tempos

${ }^{65}$ D. Fernando da Cruz, Thesouro escondido ..., cit., «Carta do confessor desta serva de Deos».

${ }^{66}$ D. Fernando da Cruz, Thesouro escondido..., cit., «Carta do confessor desta serva de Deos».

${ }^{67}$ A título de exemplo, lembremos que o exemplo de S. Mónica enquanto «perfeita viúva» foi recuperado, na época da Contrarreforma, por Fr. Francisco de Ribera (O.S.A.), em Pratica de perfecion en la vida de la perfeta biuda santa Monica N. M., Sevilla, por Francisco de Lyra, 1621, obra dedicada a D. Juana Enríquez de Ribera, marquesa de Priego, também ela uma viúva. 
pós-Trento ${ }^{68}$. Deste modo, valerá a pena evocar o caso de Anrique de Gouveia e Beatriz de Madureira, que, exemplarmente, conciliavam os deveres de esposos e pais com as práticas devocionais. Naturais e moradores no Porto, «retratos do verdadeiro, \& perfeito Matrimonio», depois de ouvirem um sermão pregado pelo padre jesuíta Francisco Estrada, resolveram «deixar o mundo, com todas suas pompas, \& vaidades, fazendo ampla doação das proprias casas em que viuião, nas mãos do B. Francisco de Borja, para morada, \& Collegio dos Religiosos» da Companhia de Jesus ${ }^{69}$. De acordo com Jorge Cardoso, fizeram voto de castidade conjugal e "vizitauão os hospitais com caridade, remediando as necessidades dos pobres cõ esmolas, curando os enfermos com suas proprias mãos, criando os filhos com sancto temor de Deos, frequentando os Sacramentos com deuoção, gastando o tempo em oração, \& penitencia, com outras penosas mortificações $»^{70}$.

Mas, entre os casos masculinos, encontramos também alguns exemplos de varões «ilustres em virtude» que merecem ser recordados.

Jorge Cardoso incluiu, no segundo tomo do seu Agiologio Lusitano, uma breve «Vida» do Doutor Inácio Ferreira $(\dagger 1629)^{71}$, casado e chanceler-mor do reino, que foi, de acordo com o mesmo autor, «mui integro» no exercício do seu cargo: mas terá sido, certamente, no domínio do exercício das virtudes e das práticas espirituais e devotas que ainda mais se terá destacado, granjeandolhe, assim, a auréola de «santidade». Deste modo, conta-nos o biógrafo que «a virtude que nella mais campeou, foi a da misericordia», pois «remediaua secretamente a muitas pessoas recolhidas, \& vergonhosas, não tendo numero as de cada hora. Cuzinhauasse em sua casa todos os dias panella mui cheirosa para pobres, \& para os prezos nalgũs particulares da semana» ${ }^{72}$. No que respeita às suas práticas espirituais e devotas, relata-nos Jorge Cardoso que o Doutor

\footnotetext{
${ }^{68}$ Nesta época, a discussão em torno da questão do matrimónio já não se centrava na polémica entre virgindade / celibato religioso e casamento, mas sim na possibilidade de se alcançar a perfeição neste segundo estado. Deste modo, a confirmação da sacramentalidade do matrimónio levou a que se fosse desenvolvendo «uma espiritualidade do casamento resultante do apelo ao cumprimento dos deveres sociais, morais e religiosos dos casados - em especial aqueles que os autores deste período consideravam e queriam fazer «bem casados» (cf. Maria de Lurdes Correia Fernandes, Espelhos, cartas e guias..., cit., p. 65).

${ }^{69}$ Jorge Cardoso, Agiologio Lusitano ..., cit, tomo II, p. 257.

${ }^{70}$ Jorge Cardoso, Agiologio Lusitano ..., cit, tomo II, p. 257.

${ }^{71}$ O Doutor Inácio Ferreira casou com D. Paula de Sá, «mui semelhante a seu marido nos dotes da natureza, \& da graça». Deste perfeito matrimónio nasceu, entre outros filhos, D. Bernarda Ferreira de Lacerda, conhecidíssima pelo seu vasto saber, que se ia desde as línguas, a Poesia e a Retórica até à Matemática e à Filosofia.

${ }^{72}$ Jorge Cardoso, Agiologio Lusitano ..., cit., tomo II, p. 488.
} 
Inácio Ferreira «commungava mui a miudo», tomava disciplina todos os dias, trazia cilício, fugia das mulheres e «tinha lição spiritual à mesa das místicas obras de Sancta Theresa, de quem era special deuoto, \& assi mesmo de sua exemplar religião; tanto que chegou a pedir o habito de Donato (...), que os prelados the negarão, pela grande falta que faria à Republica, \& aos pobres de Christo, atè chegarse a valer do Geral de Castella sem effeito»: e o mesmo «lhe succedeo cos Arrabidos, que nũqua the saião de casa» ${ }^{73}$. Com efeito, este discurso panegírico em torno de aspetos da vida moral e espiritual de um casado mostra, claramente, uma sintonia entre o estado do casamento, ajustada aos tempos pós-Trento, e a possibilidade de alcançar a perfeição cristã e, logo, a salvação eterna.

Tendo em conta esta moldura, parece-nos que valerá a pena evocar o exemplo de um outro casado, D. Tomás de Noronha: (falecido em 1588), filho de D. Leão de Noronha $^{74}$, que se distinguiu no exercício das práticas espirituais e devotas, especialmente na contínua e intensa oração, tendo falecido com fama sanctitatis, e de D. Branca de Castro, e casado com D. Helena da Silva, filha de Gil Eanes da Costa ${ }^{75}$. De acordo com o biógrafo, na oração «era continuo, gastando nella dias, \& noites inteiras de juelhos, de que veio a contrair tam duros callos, como de camelo, como se refere de Santiago Menor. Cada noite insinaua, \& doctrinaua sua família, lendolhe spiritual lição, a que nenhum auia de faltar, \& juntamente a vida do Sancto daquelle dia, declarandolhes tudo com muita particularidade, \& fruto de suas almas, de modo que parecia couento de religiosos, que casa de fidalgo secular $\rangle^{76}$.

Por tudo isto, parece-nos que a problemática abordada ao longo destas páginas merece algumas reflexões. No domínio das obras de pendor hagiográfico ou devoto, produzidas durante os séculos XVI e XVII, as «Vidas» de leigos ocupam um lugar cada vez mais significativo, mostrando, assim, a sua crescente emancipação no domínio das práticas espirituais e devotas, tributária, em larga medida, da evolução e da visibilidade que os diversos modelos de santidade leiga foram conhecendo, a partir da Baixa Idade Média. Para além dos casos apresentados, poderíamos, do mesmo modo, evocar os casos de várias leigos que optaram por um ideal de vida eremítica, especialmente a partir do século XVI,

${ }^{73}$ Jorge Cardoso, Agiologio Lusitano ..., cit.., tomo II, p. 488-489.

${ }^{74}$ José Adriano de Freitas Carvalho, "«Vida e Mercês que Deus fez ao venerável D. Leão de Noronha»: do santo de corte ao santo de família na Época Moderna em Portugal”, Via Spiritus, 3 (1996), p. 81-161.

${ }^{75}$ D. António Caetano de Sousa, História Genealógica da Casa Real Portuguesa, tomo XI, Coimbra, Atlântida, 1954, p. 530.

${ }^{76}$ Jorge Cardoso, Agiologio Lusitano..., cit., tomo I, p. 149. 
influenciadas, em boa medida, não só pelos tradicionais exemplos legados pela hagiografia (lembremos Santa Antão ou São Paulo Eremita), mas também pela significativa receção que, em alguns círculos cultos, conheceu a edição de uma tradução do Boosco Deleitoso, impressa por Hermão de Campos, em 1515, que aproveitava, largamente, o De Vita Solitaria, de Petrarca. De facto, estas «Vidas» exemplares, que espelham a apropriação de modelos hagiográficos, que muito glorificavam a Igreja católica, e refletem mimetismos vários, veiculam exemplos de perfeição, passíveis de renovadas imitações. Em todo o caso, a variedade de casos apresentados pelas obras estudadas, escorados em um discurso retórico que procurava seduzir o(s) público(s) leitor(es), mostram como os autores, recorrendo a exemplos de figuras reais, procuravam convencê-lo(s) de que a perfeição cristã, que asseguraria a salvação eterna, era algo acessível a todos os fiéis e possível em todos os estados. De facto, o significativo número de leigos imbuídos de preocupações espirituais, cuja «Vida» encontramos relatada nas fontes que respigámos, merece uma atenção particular, na medida em que o seu estudo poderá lançar novas luzes interpretativas sobre as relações da História da espiritualidade com os outros ramos da História. 